\title{
What are the Perspectives of Stakeholders on Integrated Development in Nigeria? Findings from a Survey among Program Managers, Donors and Policymakers
}

\author{
Edward Adekola Oladele ${ }^{1 *}$, Tolulope Oladele ${ }^{2}$, Utibe Ebong $^{3}$, Olusesan Ayodeji Makinde ${ }^{3}$, \\ Robert Chiegil ${ }^{1}$ \\ ${ }^{1}$ Department of Infectious Diseases and Health Systems Strengthening, FHI 360, Abuja, \\ Nigeria \\ ${ }^{2}$ Directorate of Community Prevention and Care Services, National Agency for Control of \\ AIDS, Abuja, Nigeria \\ ${ }^{3}$ Viable Knowledge Masters, Abuja, Nigeria \\ ${ }^{4}$ West Africa and Middle East Regional Office, FHI 360, North Carolina, USA
}

\begin{abstract}
Integrated development generally refers to integrated implementation of quality interventions within or across sectors aimed at stimulating development. Funders/donors, policymakers, and programme managers are key stakeholder groups that determine the success of integrated development interventions. A shared convergence in their perspectives enables joint plans and actions. Our objectives were to determine the perspectives of integrated development, among selected stakeholder groups in Nigeria, and to discuss implications for practice. This was a quantitative survey. We used a multi-stage random sampling technique to select a representative sample of 301 key stakeholders in Nigeria. We analysed the data using SPSS. Almost half (49.5\%) of these respondents were senior level stakeholders and 46.5\% of them had over 10 years of experience. Respondents' perspectives of the meaning of integrated development varied. Respondents mostly (69.8\%) felt that ID meant multisectoral interventions. Perspectives also varied by stakeholder type, sector and characteristics. Enhancing collaborations and strengthening human capacity was the predominant benefit among funders/donors (70.4\%) while the most predominantly expressed benefit among the policy makers (78.9\%) and programme managers (78.3\%) was that ID yields more impactful and sustainable interventions. These findings clearly show that nuanced communication of integrated development is needed to achieve consensus and programme success.
\end{abstract}

Keywords: Integrated development, Nigeria, Stakeholder perspectives.

\section{Introduction}

Integrated development generally refers to integrated implementation of quality interventions within or between sectors aimed at stimulating development. While there is no commonly agreed definition, a recently proposed definition captures multiple concepts that embody integrated development. This definition describes integrated development as "an intentional approach that links the design, delivery and evaluation of programs across disciplines and sectors to produce an amplified, lasting impact on people's lives" [1].

The necessity of integrated development to tackle the challenges that individuals and their families face which tend to perpetuate the cycle of ignorance, poverty and disease has been argued for by many authors [2-12]. The argument for integrated development often stems from the recognition that poor development is rooted in multiple interplaying 
factors from different sectors. Irrespective of the school of thought to which authors belong, there is a general agreement that development is about improvement in standards of living and these improvements are usually not from just a single sector [13, 14]. The United Nations Development Program (UNDP) in the Human Development Reports from 1990 to 2016, has continued to emphasize that development must be about people and the multiple factors that interplays to bring about development $[5,15$, 16]. This seems intuitive but there are counterarguments [17, 18].

Generally, integrated development, is expected to enhance service efficiency, quality, and maximize the use of resources and opportunities $[19,20]$. Whether within or across sectors, integrated development requires the collaborative interplay of multiple stakeholders at multiple levels whose perspectives may vary. These variations define the existing understanding of integration. The motivation of stakeholders in integrated development is polarized by their perspectives, interests, and disposition. While in the perspectives of some scholars, integrated development should be extoled for its benefits, others warn that integrated development also poses some risks to systems. The different stakeholder perspectives often determine what is considered success or failure [21].

In this wise, key groups of stakeholders could be considered as funders/donors, policymakers, programme managers, service providers and end users/beneficiaries [1, 21-23].

The first three of these stakeholder groups determine if integrated development as an approach predominates the thinking in the development landscape. A shared point of convergence in their perspectives enables them to plan actions or approaches together [24]. This study therefore focused on this group of stakeholders. The differences in these perspectives centre around the costs, benefits and challenges of integrated development. Our objectives were to determine the perspectives of integrated development, among selected stakeholder groups in Nigeria, and to examine the implications of these perspectives on the practice of integrated development in Nigeria.

\section{Methods}

\section{Study Design}

This was a quantitative survey.

\section{Study Population}

The selected stakeholders of interest in this study were funders/donors, policy makers, and programme managers in Nigeria. These stakeholder groups influence the prevailing integrated development discourse.

\section{Sample Size and Sampling Method}

A representative sample was selected in a multistage sampling procedure. In stage 1, institutions to visit were selected. The sampling frame for this stage consisted of a listing of all agencies with headquarters in the administrative headquarters of the country - Abuja. This list of 217 entities was derived from a comprehensive list of federal ministries, parastatals and agencies, international agencies and nongovernmental organizations in Abuja [25-28]. The list of 217 was examined for duplicates and trimmed down to 205 after duplicates were removed. The 205 unique entries were further examined to determine those with a focus on development and health. This brought down the list to 65. From these 65, a random sample of 26 $(40 \%)$ were included as the entities to visit. The process and details are presented in Figure 1.

For stage 2, the sample size was calculated using the Leslie Fischer formula $-n=z^{2} p q / d^{2}$. Using the parameters $-\mathrm{z}$ as $1.96, \mathrm{p}$ as 0.75 , $\mathrm{q}$ as 0.25 and $\mathrm{d}$ as 0.05 , gave a minimum sample size of 288. Given an allowance of $10 \%$ nonresponse/invalid responses, the number of questionnaires distributed was adjusted upwards to 316. Making this adjustment in the number of questionnaires distributed is in line with the assertion of Gill and Johnson (2010) who note that the sample sizes reflect the number of 
obtained responses, and not necessarily the number of questionnaires distributed [29]. The aim was to achieve obtained responses meeting the calculated sample size of 288 . The 316 samples were then distributed proportionally into the 26 organizations. Questionnaires were administered till the sample size was completed.

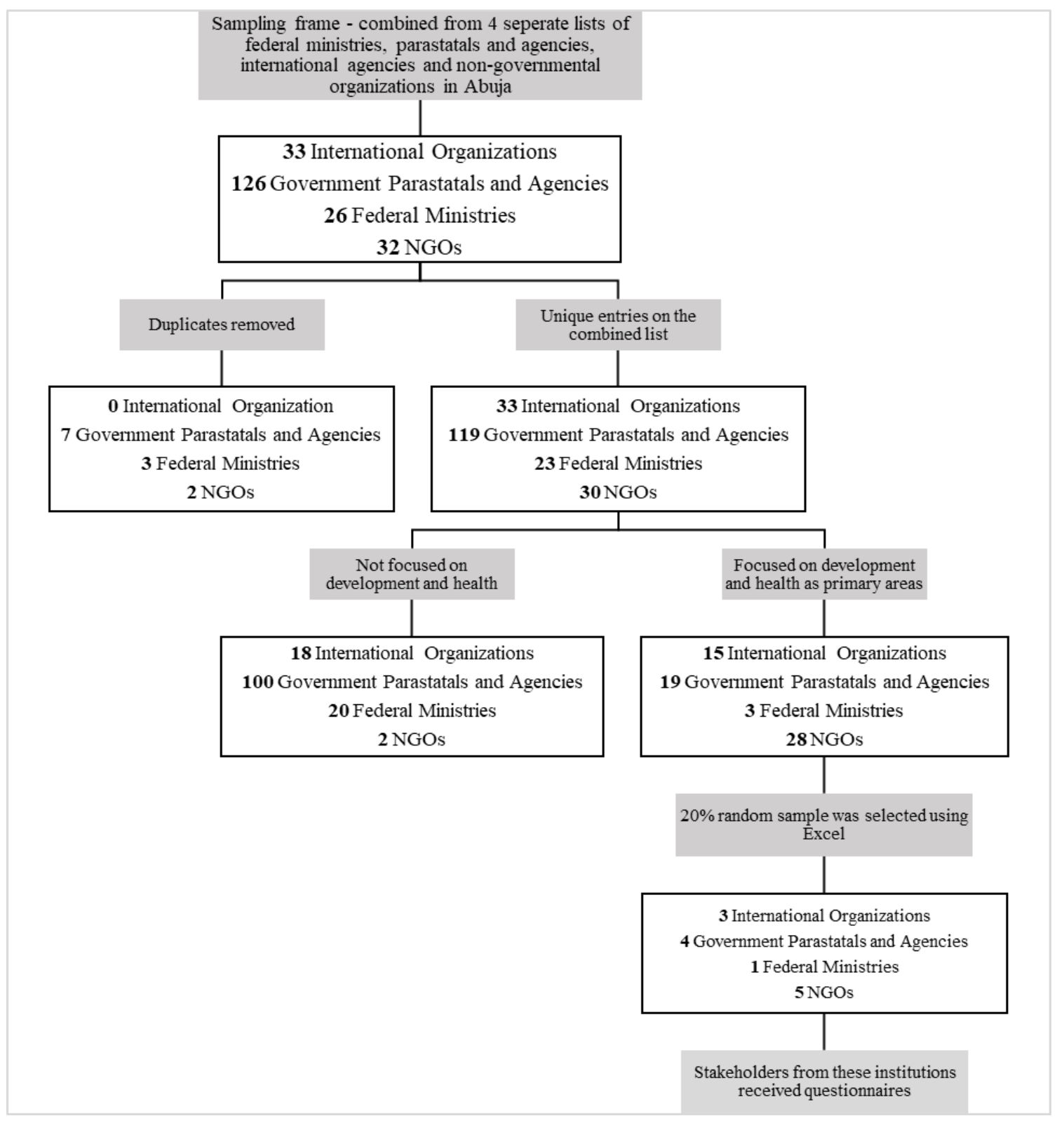

Figure 1. Sampling Approach

\section{Data Collection}

Questionnaires

were

respondent administered. The questionnaire was examined for internal consistency twice (after 12 and after all respondents had been received) using the Cronbach's alpha [30]. Using the 'Analyze $\rightarrow$ Scale $\rightarrow$ Reliability Analysis' module in SPSS version 25 [31] and interpreted following the rule of George and Mallery [32] On both runs of
Cronbach's Alpha, the internal consistency of the items was rated to be acceptable ( 0.75 and $0.77)$ and good (0.82 and 0.80) when based on standardized items.

Data from all 301 stakeholders who responded were collected over a 3-week period between $15^{\text {th }}$ February and $5^{\text {th }}$ March 2020 . Once the questionnaires were completed, the data 
from filled forms were then entered into SPSS software version 25 [31].

\section{Analysis}

Data entered into SPSS [31] from the questionnaires were cleaned and then analyzed. Using the 'Analyze $\rightarrow$ Descriptive Statistics $\rightarrow$ Frequencies' module of SPSS, basic frequencies of all variables in the dataset were generated to examine the structure of the data. The basic frequencies also were used to describe stakeholder characteristics and a descriptive summary of stakeholder perspectives. These were presented as tables.

Using the 'Analyze $\rightarrow$ Descriptive Statistics $\rightarrow$ Tables $\rightarrow$ Custom Tables/Multiple Response Sets' module of SPSS, cross tabulations were then done to examine patterns and the influence of stakeholder characteristics on expressed perspectives. Associations were examined using the chi-square statistic at a significance level of $5 \%$. Using this module allowed the researcher to determine table set up, exclusion of items and thorough examination of the data while generating the crosstabulations. This module also helped identify within each crosstabulation, the significant relationships and exclusions of items that may violate rules that ensure the validity of the Chi-square test statistic.

\section{Ethical Approval}

Ethical approval was obtained from the national ethics review board - National Health Research Ethics Committee (NHREC).

\section{Results}

\section{Characteristics of Respondents}

Quantitative data were collected from a total of 301 stakeholders in Nigeria. Almost half (149, $49.5 \%$ ) of these respondents were senior level stakeholders with others being mid-level (111, $36.9 \%)$ and junior level (41, 13.6\%). Most stakeholders $(140,46.5 \%)$ had over 10 years of experience, followed by 93 (30.9\%) with 5 to 10 years and $68(22.6 \%)$ with less than 5 years' experience in their given sector. There were more male $(185,61.5 \%)$ than female (116, $38.5 \%)$ respondents. It was also observed that about two-thirds $(66.4 \%)$ of the stakeholders held at least a master's degree as their highest level of education while 87 (28.9\%) held a Bachelor's degree and only 14 (4.7\%) held a diploma as their highest level of education attained.

More than half $(174,57.8 \%)$ of the respondents had worked in the development sector for most of their career. The private sector had $28(9.3 \%)$, government ministries/parastatal $46(15.3 \%)$, hospitals or other health institutions had $53(17.6 \%)$ of the respondents. Stakeholders self-categorized themselves as Funder/Donor (27, 9.0\%), Policy Maker (76, 25.2\%), Programme Manager $(184,61.1 \%)$ and Others $(14,4.7 \%)$.

\section{Descriptive Findings}

\section{Phrases that Portray the Meaning of Integrated Development and Key Differentiating Features}

Respondents' perspectives of the meaning of integrated development varied. Respondents mostly (69.8\%) felt that ID meant multi-sectoral interventions. This was followed closely by the perspective that ID meant a pooling of resources (40.9\%). Only one respondent felt that ID was about holistic programming just as well as only one respondent felt that ID was about integrating different methodologies.

More than 8 of every 10 respondents felt that ID could be told apart from vertical programmes by the effective collaborations, communication, consensus built, and cost effectiveness achieved. About half of respondents (51.0\%) also felt that ID, as different from vertical programmes, involved leveraging on the resources and activities of other programmes. While not always so, about one third of respondents (36.7\%) felt that ID was always intersectoral. Only one respondent felt that the monitoring of ID is all inclusive or the metrics holistic. The responses are presented in Table 1 . 
Table 1. Meaning and Key Features of Integrated Development

\begin{tabular}{|l|l|l|}
\hline Features & N & Percent \\
\hline Meaning of integrated development (multiple responses allowed) \\
\hline Multi-sectoral intervention & 210 & $69.8 \%$ \\
\hline Pooling resources (human, material and finance) & 123 & $40.9 \%$ \\
\hline Roundtable collaboration with other stakeholders & 116 & $38.5 \%$ \\
\hline Central coordination mechanism & 91 & $30.2 \%$ \\
\hline Joint implementation of two separate programs & 88 & $29.2 \%$ \\
\hline Co-location of services & 55 & $18.3 \%$ \\
\hline Holistic programming that connects various components & 1 & $0.3 \%$ \\
\hline Integrating different methodologies & 1 & $0.3 \%$ \\
\hline Key features of integrated development (multiple responses allowed) & \\
\hline $\begin{array}{l}\text { Involves effective collaborations, communications, consensus } \\
\text { and cost-effectiveness }\end{array}$ & 250 & $83.3 \%$ \\
\hline Involves leveraging on the resources and activities of others & 153 & $51.0 \%$ \\
\hline Always inter-sectoral & 110 & $36.7 \%$ \\
\hline Vast in scope & 77 & $25.7 \%$ \\
\hline $\begin{array}{l}\text { Monitoring and evaluation are all inclusive and success is } \\
\text { measured holistically }\end{array}$ & 1 & $0.3 \%$ \\
\hline
\end{tabular}

Stage of the Project Cycle when Integrated Development should be Applied and Sectoral Preference

About 8 of every 10 respondents felt that ID should be applied at the pre-planning stage of projects with the least number of respondents (40.9\%) expressing that ID can be applied at the evaluation stage of the project cycle. About half (49.8\%) felt that ID should be applied during implementation. These are shown in Figure 2.

Respondents expressed that ID could happen within a single sector $(84,27.9 \%)$, across similar sectors $(113,37.5 \%)$, or across any sectors without limitations (104, 34.6\%).

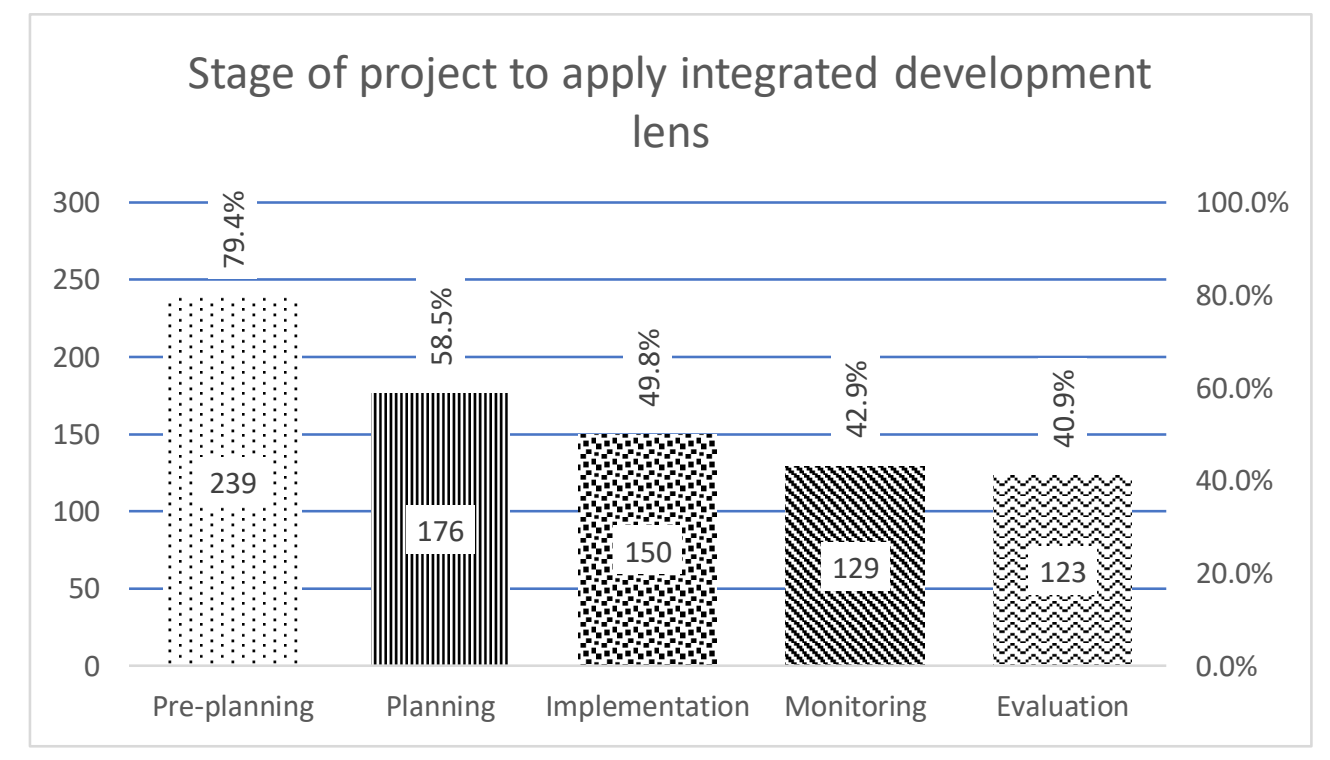

Figure 2: Stage of Project to Apply ID Approach 


\section{Benefits of Integrated Development}

Stakeholders were varied in the different benefits of ID that they expressed. Majority of respondents $(243,80.7 \%)$ felt that a benefit of ID was that it yields more impactful and sustainable interventions than other approaches. Overall, the next most expressed benefit was that ID fosters collaborations and strengthens human capacity (223, 74.1\%). The least expressed benefit was the ID was cost effective. Only a little more than half $(176,58.5 \%)$ felt that ID was cost effective. Other perspectives are summarized in Table 2.

Table 2. Respondents' Perspectives on Benefits of ID

\begin{tabular}{|l|l|l|}
\hline Benefits of ID & N & Percent \\
\hline Yields more impactful and sustainable interventions & 243 & $80.7 \%$ \\
\hline Fosters collaborations and strengthens human capacity & 223 & $74.1 \%$ \\
\hline Adds value to end-users and beneficiaries & 180 & $59.8 \%$ \\
\hline Enhances communication (among staff and sectors) & 179 & $59.5 \%$ \\
\hline Cost effective & 176 & $58.5 \%$ \\
\hline Do you think ID is beneficial to donors/funders? & \multicolumn{2}{|l|}{} \\
\hline Yes & 258 & $85.7 \%$ \\
\hline No & 4 & $1.3 \%$ \\
\hline Difficult to say & 39 & $13.0 \%$ \\
\hline Do you think ID is beneficial to beneficiaries/clients/end-users? & \multicolumn{2}{|l|}{} \\
\hline Yes & 281 & 93.4 \\
\hline No & 3 & 1.0 \\
\hline Difficult to say & 17 & 5.6 \\
\hline Total & 301 & $100.0 \%$ \\
\hline
\end{tabular}

\section{Trade-offs between Programs to Achieve Integrated Development}

When asked about trade-offs between programs in order to achieve ID, 232 (77.1\%) of stakeholders responded in the affirmative and 69 (22.9\%) said 'no'. Of the 232 who felt that tradeoffs were necessary, 176 (75.9\%) expressed that the impact on individual programs was an improved program quality while $56(24.1 \%)$ felt it reduced program quality. Close to 9 of every $10(207,89.2 \%)$ persons who felt that trade-offs were necessary felt that the trade-offs should not lead to a jettisoning of ID as an approach but 25 (10.8\%) felt otherwise. As perspectives varied between stakeholders, they were asked if ID should be implemented with some form of restrictions that will cater for their concerns with ID. Majority $(117,38.9 \%)$ thought this should not be the case, some were undecided (100,
$33.2 \%)$ and others responded in the affirmative $(84,27.9 \%)$.

\section{Challenges of Integrated Development and Perspectives Regarding Costs}

That there may have to be technical compromise between programs being integrated was the most expressed challenge with ID. This was expressed by 165 (54.8\%) respondents. Other challenges expressed included that ID can be difficult to coordinate and manage (45.5\%), comprised complex processes (43.2\%), can be capital intensive $(41.2 \%)$, and that it requires longer project duration (35.2\%).

Stakeholders had raised costs as an issue of importance during the key informant interviews. During the quantitative interviews, the majority of respondents (62.8\%) opined that ID was initially costly but eventually led to cost savings. 
Only 23 respondents (7.6\%) felt that ID was more expensive than vertical programs. The cost of capacity building for human resources was the item expressed by most stakeholders as an important cost element to consider. Other cost elements were coordination costs $(61.5 \%)$ and program inputs $(53.2 \%)$. Only three (1.0\%) respondents mentioned monitoring and evaluation costs as important. These views are presented in Table 3.

\section{Pattern of Perspectives of Integrated} Development by Stakeholder Type and Sector

Meaning of Integrated Development by Stakeholder Type and Sector

The notion that IDS entailed multi-sectoral interventions was most greatly expressed by stakeholders from funder/donor organizations
(77.8\%); followed by about 7 of every 10 program managers and about two-thirds $(68.4 \%)$ of policy makers. The pattern was different when considering the perspective that ID largely entailed effective collaborations, communications, consensus and cost-efficiency. Most respondents of the policy makers group $(86.8 \%)$ expressed this as their perspective while $83.6 \%$ of programme managers and $77.8 \%$ of funders/donors held the same view. For all stakeholder groups, the second most stated perspective was that ID involved pooling of resources. Indeed, this was the perspective expressed by more than half $(51.9 \%)$ of funder/donor staff. Stakeholder type did not account for statistically significant differences in perspectives at the 5\% significance level $(\mathrm{p}=$ $0.591)$.

Table 3. Challenges of ID and Stakeholder Perspectives on Cost Considerations

\begin{tabular}{|c|c|c|}
\hline & $\mathbf{N}$ & Percent \\
\hline \multicolumn{3}{|l|}{ Challenges of ID } \\
\hline Technical compromise & 165 & $54.8 \%$ \\
\hline Difficult to coordinate and manage & 137 & $45.5 \%$ \\
\hline Complex processes & 130 & $43.2 \%$ \\
\hline Capital intensive & 124 & $41.2 \%$ \\
\hline Requires longer project duration & 106 & $35.2 \%$ \\
\hline Total & 301 & $100.0 \%$ \\
\hline \multicolumn{3}{|c|}{$\begin{array}{l}\text { Which of the following statement agrees most closely with your views } \\
\text { regarding cost of integrated development interventions? }\end{array}$} \\
\hline Initially costly but eventually leads to cost savings & 189 & $62.8 \%$ \\
\hline More expensive than vertical programs & 23 & $7.6 \%$ \\
\hline Saves cost right from the start & 89 & $29.6 \%$ \\
\hline Total & 301 & $100.0 \%$ \\
\hline \multicolumn{3}{|c|}{ Important cost elements to consider (multiple responses allowed) } \\
\hline Coordination cost & 185 & $61.5 \%$ \\
\hline Cost of program inputs & 160 & $53.2 \%$ \\
\hline Cost of human resource capacity building & 193 & $64.1 \%$ \\
\hline Monitoring and evaluation costs & 3 & $1.0 \%$ \\
\hline
\end{tabular}

In all sectors, the majority of stakeholders perceived ID to be multisectoral interventions. Stakeholder perspectives varied depending on their sector. NGO/development sector and government ministry stakeholders mostly felt that ID meant multisectoral interventions (73.6\% and $63.0 \%$ ), followed by pooling resources (42.0\% and $43.5 \%)$, roundtable collaborations 
(40.2\% and $37.0 \%)$, and then having a central coordination mechanism (35.1\% and 32.6\%). Stakeholders in hospitals or health institutions responded in the order - multisectoral interventions, pooling resources, roundtable collaborations, and joint implementation of two separate programs. The private sector however had multisectoral interventions (57.1\%) followed by roundtable collaborations (32.1\%), pooling resources $(28.6 \%)$ and then having a central coordination mechanism $(25.0 \%)$ as the top four meanings from each of these stakeholder sectors. These are presented in Table 4.

\section{Benefits of Integrated Development by Stakeholder Type and Sector}

As regards perspectives on the benefits of ID, enhancing collaborations and strengthening human capacity was the predominant benefit among funders/donors (70.4\%), and the second most expressed benefit among policy makers (71.1\%) and programme managers (78.3\%). The most predominantly expressed benefit among the policy makers $(78.9 \%)$ and programme managers $(78.3 \%)$ was that ID yields more impactful and sustainable interventions. Of all the benefits listed, funders/donors (51.9\%) and programme managers $(59.2 \%)$ were least likely to consider cost effectiveness as a benefit. The least likely benefit expressed by policy makers was that ID enhances communication.

The influence of sector on perspectives of benefits of ID was such that there was convergence of perspectives around the fact that ID yields more impactful and sustainable interventions. This was the most expressed benefit of ID regardless of the sector. This predominant perspective was followed by the fact that ID fosters collaboration. Private sector stakeholders were however only minimally likely to consider cost-effectiveness as a benefit, with less than $30.0 \%$ of stakeholders from that sector mentioning cost effectiveness as a benefit. This was the lowest proportion of any sector. The variations in perspectives on the benefits of
ID were significant at the $5 \%$ level. The analysis is presented in Table 5 .

\section{Stakeholder Perspectives on ID Cost Considerations}

Different stakeholder groups expressed varied perspectives on which cost considerations were important for ID. The single point of convergence in perspectives was that all stakeholders felt that monitoring and evaluation costs were not important considerations. The pattern of emphasis on other cost categories however differed among the different stakeholders. The highest proportion of any stakeholder group who expressed human resource capacity building costs as a key consideration were the funders/donors $(74.1 \%)$. Funders/donors had the least proportion (48.1\%) expressing program input costs as a key consideration. Policy makers expressed almost equal emphasis on coordination costs $(57.9 \%)$, program inputs $(57.9 \%)$ and human resource capacity building $(51.3 \%)$ with the latter getting the lowest proportion. Programme managers also placed more emphasis on coordination $(64.1 \%)$ and human resource capacity building costs $(67.4 \%)$.

The perspectives on cost of ID showed that stakeholders from different sectors were more likely to place emphasis on different cost elements. The cost element least considered important by all sectors was the monitoring and evaluation cost. That was however the only point of convergence. Development sector workers (69.5\%), health institutions based (64.2\%) and private sector $(64.3 \%)$ mostly considered human resource capacity building, while government ministries workers mostly $(69.6 \%)$ considered coordination cost as the important cost elements. Table 6 presents the full cascade of results from this analysis. The observed patterns were not statistically significant at the $5 \%$ level.

\section{Challenges with Integrated Development}

Stakeholders expressed challenges with ID. For funders/donors, ID may be capital intensive 
was the most expressed challenge - 59.3\%. For policy makers and programme managers, it was that there might be needs for technical compromise between areas involved in ID. Requiring a longer project duration as a result of ID was the least expressed challenge by funders/donors and was only expressed by a third of respondents from that stakeholder group. Across different stakeholders, this perspective was similarly expressed by only about a third of policy makers and programme managers. This represents a convergence.

The perspectives on challenges of ID varied by sector. Most stakeholders from the development sector (59.8\%), government ministries (56.5\%) and health institutions (50.9\%) listed technical compromise as a challenge with ID. The majority of respondents from the private sector (39.3\%) however considered complex processes and requiring longer project durations as their major challenges. The development sector $(36.3 \%)$ and health institution based (32.1\%) stakeholders were least likely to report requiring longer project duration as a challenge with ID. Government ministry stakeholders were on the other hand least likely to report complex processes as their challenge with ID. These variations were statistically significant at the 5\% level. The details are presented in Table . 
Table 4. Distribution of Perspectives on Meaning of ID by Stakeholder Type and Sector

\begin{tabular}{|c|c|c|c|c|c|c|c|c|c|}
\hline \multirow{2}{*}{$\begin{array}{l}\text { Meaning of } \\
\text { integrated development }\end{array}$} & \multicolumn{4}{|c|}{ Stakeholder Type } & \multicolumn{5}{|c|}{ Stakeholder Sector } \\
\hline & Funder/Donor & Policy Maker & $\begin{array}{l}\text { Programme } \\
\text { Manager }\end{array}$ & Total & $\begin{array}{l}\text { NGO or } \\
\text { Development } \\
\text { Sector }\end{array}$ & $\begin{array}{l}\text { Government } \\
\text { Ministry or } \\
\text { Parastatal }\end{array}$ & $\begin{array}{l}\text { Hospitals or } \\
\text { Other Health } \\
\text { Institutions }\end{array}$ & $\begin{array}{l}\text { Private } \\
\text { Sector }\end{array}$ & Total \\
\hline \multirow{2}{*}{$\begin{array}{l}\text { Multi-sectoral } \\
\text { intervention }\end{array}$} & 21 & 52 & 128 & 201 & 128 & 29 & 37 & 16 & 210 \\
\hline & $(77.8 \%)$ & $(68.4 \%)$ & $(69.6 \%)$ & $70.0 \%$ & $(73.6 \%)$ & $(63.0 \%)$ & $(69.8 \%)$ & $(57.1 \%)$ & $(69.8 \%)$ \\
\hline \multirow{2}{*}{$\begin{array}{l}\text { Central coordination } \\
\text { mechanism }\end{array}$} & 12 & 24 & 52 & 88 & 61 & 15 & 8 & 7 & 91 \\
\hline & $(44.4 \%)$ & $(31.6 \%)$ & $(28.3 \%)$ & $30.7 \%$ & $(35.1 \%)$ & $(32.6 \%)$ & $(15.1 \%)$ & $(25.0 \%)$ & $(30.2 \%)$ \\
\hline \multirow{2}{*}{$\begin{array}{l}\text { Pooling resources } \\
\text { (human, material and } \\
\text { finance) }\end{array}$} & 14 & 29 & 77 & 120 & 73 & 20 & 22 & 8 & 123 \\
\hline & $(51.9 \%)$ & $(38.2 \%)$ & $(41.8 \%)$ & $41.8 \%$ & $(42.0 \%)$ & $(43.5 \%)$ & $(41.5 \%)$ & $(28.6 \%)$ & $(40.9 \%)$ \\
\hline \multirow{2}{*}{$\begin{array}{l}\text { Roundtable } \\
\text { collaboration with other } \\
\text { stakeholders }\end{array}$} & 13 & 28 & 73 & 114 & 70 & 17 & 20 & 9 & 116 \\
\hline & $(48.1 \%)$ & $(36.8 \%)$ & $(39.7 \%)$ & $39.7 \%$ & $(40.2 \%)$ & $(37.0 \%)$ & $(37.7 \%)$ & $(32.1 \%)$ & $(38.5 \%)$ \\
\hline \multirow[t]{2}{*}{ Co-location of services } & 6 & 9 & 40 & 55 & 42 & 5 & 6 & 2 & 55 \\
\hline & $(22.2 \%)$ & $(11.8 \%)$ & $(21.7 \%)$ & $19.2 \%$ & $(24.1 \%)$ & $(10.9 \%)$ & $(11.3 \%)$ & $(7.1 \%)$ & $(18.3 \%)$ \\
\hline \multirow{2}{*}{$\begin{array}{l}\text { Joint implementation of } \\
\text { two separate programs }\end{array}$} & 10 & 19 & 57 & 86 & 61 & 13 & 10 & 4 & 88 \\
\hline & $(37.0 \%)$ & $(25.0 \%)$ & $(31.0 \%)$ & $30.0 \%$ & $(35.1 \%)$ & $(28.3 \%)$ & $(18.9 \%)$ & $(14.3 \%)$ & $(29.2 \%)$ \\
\hline \multirow{2}{*}{$\begin{array}{l}\text { Integrating different } \\
\text { methodologies }\end{array}$} & 0 & 0 & 1 & 1 & 0 & 0 & 0 & 1 & 1 \\
\hline & $(0.0 \%)$ & $(0.0 \%)$ & $(0.5 \%)$ & $0.3 \%$ & $(0.0 \%)$ & $(0.0 \%)$ & $(0.0 \%)$ & $(3.6 \%)$ & $(0.3 \%)$ \\
\hline \multirow{2}{*}{$\begin{array}{l}\text { Holistic programming } \\
\text { that connects various } \\
\text { components }\end{array}$} & - & - & - & - & 1 & 0 & 0 & 0 & 1 \\
\hline & & & & & $(0.6 \%)$ & $(0.0 \%)$ & $(0.0 \%)$ & $(0.0 \%)$ & $(0.3 \%)$ \\
\hline \multirow[t]{3}{*}{ Total } & 27 & 76 & 184 & 287 & 174 & 46 & 53 & 28 & 301 \\
\hline & $(100.0 \%)$ & $(100.0 \%)$ & $(100.0 \%)$ & $(100.0 \%)$ & $(100.0 \%)$ & $(100.0 \%)$ & $(100.0 \%)$ & $(100.0 \%)$ & $(100.0 \%)$ \\
\hline & \multicolumn{4}{|l|}{$\mathrm{p}$-value $=0.591$} & \multicolumn{5}{|c|}{$\mathrm{p}$-value $=0.007$} \\
\hline
\end{tabular}


Table 5. Distribution of Perspectives on Benefits of ID by Stakeholder Type and Sector

\begin{tabular}{|c|c|c|c|c|c|c|c|c|c|}
\hline \multirow[b]{2}{*}{ Benefits of ID } & \multicolumn{4}{|c|}{ Stakeholder type } & \multicolumn{5}{|c|}{ Stakeholder sector } \\
\hline & $\begin{array}{l}\text { Funder/Do } \\
\text { nor }\end{array}$ & $\begin{array}{l}\text { Policy } \\
\text { Maker }\end{array}$ & $\begin{array}{l}\text { Programme } \\
\text { Manager }\end{array}$ & Total & $\begin{array}{l}\text { NGO or } \\
\text { Development } \\
\text { Sector } \\
\end{array}$ & $\begin{array}{l}\text { Government } \\
\text { Ministry or } \\
\text { Parastatal } \\
\end{array}$ & $\begin{array}{l}\text { Hospitals or } \\
\text { Other Health } \\
\text { Institutions } \\
\end{array}$ & $\begin{array}{l}\text { Private } \\
\text { Sector }\end{array}$ & Total \\
\hline \multirow[t]{2}{*}{ Cost effective } & 14 & 48 & 109 & 171 & 111 & 26 & 31 & 8 & 176 \\
\hline & $(51.9 \%)$ & $(63.2 \%)$ & $(59.2 \%)$ & $(59.6 \%)$ & $(63.8 \%)$ & $(56.5 \%)$ & $(58.5 \%)$ & $(28.6 \%)$ & $(58.5 \%)$ \\
\hline \multirow{2}{*}{$\begin{array}{l}\text { Adds value to end-users and } \\
\text { beneficiaries }\end{array}$} & 15 & 46 & 112 & 173 & 112 & 26 & 31 & 11 & 180 \\
\hline & $(55.6 \%)$ & $(60.5 \%)$ & $(60.9 \%)$ & $(60.3 \%)$ & $(64.4 \%)$ & $(56.5 \%)$ & $(58.5 \%)$ & $(39.3 \%)$ & $(59.8 \%)$ \\
\hline \multirow{2}{*}{$\begin{array}{l}\text { Enhances communication } \\
\text { (among staff and sectors) }\end{array}$} & 15 & 43 & 116 & 174 & 112 & 25 & 32 & 10 & 179 \\
\hline & $(55.6 \%)$ & $(56.6 \%)$ & $(63.0 \%)$ & $(60.6 \%)$ & $(64.4 \%)$ & $(54.3 \%)$ & $(60.4 \%)$ & $(35.7 \%)$ & $(59.5 \%)$ \\
\hline \multirow{2}{*}{$\begin{array}{l}\text { Fosters collaborations and } \\
\text { strengthens human capacity }\end{array}$} & 19 & 54 & 144 & 217 & 135 & 32 & 39 & 17 & 223 \\
\hline & $(70.4 \%)$ & $(71.1 \%)$ & $(78.3 \%)$ & $(75.6 \%)$ & $(77.6 \%)$ & $(69.6 \%)$ & $(73.6 \%)$ & $(60.7 \%)$ & $(74.1 \%)$ \\
\hline \multirow{2}{*}{$\begin{array}{l}\text { Yields more impactful and } \\
\text { sustainable interventions }\end{array}$} & 18 & 60 & 155 & 233) & 146 & 36 & 43 & 18 & 243 \\
\hline & $(66.7 \%)$ & $(78.9 \%)$ & $(84.2 \%)$ & $(81.2 \%)$ & $(83.9 \%)$ & $(78.3 \%)$ & $(81.1 \%)$ & $(64.3 \%)$ & $(80.7 \%)$ \\
\hline \multirow[t]{3}{*}{ Total } & 27 & 76 & 184 & 287 & 174 & 46 & 53 & 28 & 301 \\
\hline & $(100.0 \%)$ & $(100.0 \%)$ & $(100.0 \%)$ & $(100.0 \%)$ & $(100.0 \%)$ & $(100.0 \%)$ & $(100.0 \%)$ & $(100.0 \%)$ & $(100.0 \%)$ \\
\hline & \multicolumn{4}{|c|}{ p-value $=0.469$} & \multicolumn{5}{|c|}{$\mathrm{p}$-value $=0.001$} \\
\hline
\end{tabular}

**Total percentages do not equal $100 \%$ because responses to questions were not mutually exclusive

Table 6. Distribution of Perspectives on ID Cost Considerations by Stakeholder Type and Sector

\begin{tabular}{|c|c|c|c|c|c|c|c|c|c|}
\hline \multirow[b]{2}{*}{$\begin{array}{l}\text { Important cost elements } \\
\text { to consider }\end{array}$} & \multicolumn{4}{|c|}{ Stakeholder type } & \multicolumn{5}{|c|}{ Stakeholder sector } \\
\hline & Funder/Donor & $\begin{array}{l}\text { Policy } \\
\text { Maker }\end{array}$ & $\begin{array}{l}\text { Programme } \\
\text { Manager }\end{array}$ & Total & $\begin{array}{l}\text { NGO or } \\
\text { Development } \\
\text { Sector }\end{array}$ & $\begin{array}{l}\text { Government } \\
\text { Ministry or } \\
\text { Parastatal } \\
\end{array}$ & $\begin{array}{l}\text { Hospitals or } \\
\text { Other Health } \\
\text { Institutions } \\
\end{array}$ & $\begin{array}{l}\text { Private } \\
\text { Sector }\end{array}$ & Total \\
\hline \multirow[t]{2}{*}{ Coordination cost } & 16 & 44 & 118 & 178 & 112 & 32 & 28 & 13 & 185 \\
\hline & $(59.3 \%)$ & $(57.9 \%)$ & $(64.1 \%)$ & $(62.0 \%)$ & $(64.4 \%)$ & $(69.6 \%)$ & $(52.8 \%)$ & $(46.4 \%)$ & $(61.5 \%)$ \\
\hline Cost of program inputs & 13 & 44 & 95 & 152 & 93 & 24 & 30 & 13 & 160 \\
\hline
\end{tabular}




\begin{tabular}{|c|c|c|c|c|c|c|c|c|c|}
\hline & $(48.1 \%)$ & $(57.9 \%)$ & $(51.6 \%)$ & $(53.0 \%)$ & $(53.4 \%)$ & $(52.2 \%)$ & $(56.6 \%)$ & $(46.4 \%)$ & $(53.2 \%)$ \\
\hline \multirow{2}{*}{$\begin{array}{l}\text { Cost of human resource } \\
\text { capacity building }\end{array}$} & 20 & 39 & 124 & 183 & 121 & 20 & 34 & 18 & 193 \\
\hline & $(74.1 \%)$ & $(51.3 \%)$ & $(67.4 \%)$ & $(63.8 \%)$ & $(69.5 \%)$ & $(43.5 \%)$ & $(64.2 \%)$ & $(64.3 \%)$ & () \\
\hline \multirow{2}{*}{$\begin{array}{l}\text { Monitoring and evaluation } \\
\text { costs }\end{array}$} & 0 & 1 & 1 & 2 & 3 & 0 & 0 & 0 & 3 \\
\hline & $(0.0 \%)$ & $(1.3 \%)$ & $(0.5 \%)$ & $(0.7 \%)$ & $(1.7 \%)$ & $(0.0 \%)$ & $(0.0 \%)$ & $(0.0 \%)$ & $(1.0 \%)$ \\
\hline \multirow[t]{3}{*}{ Total } & 27 & 76 & 184 & 287 & 174 & 46 & 53 & 28 & 301 \\
\hline & $(100.0 \%)$ & $(100.0 \%)$ & $(100.0 \%)$ & $(100.0 \%)$ & $(100.0 \%)$ & $(100.0 \%)$ & $(100.0 \%)$ & $(100.0 \%)$ & $(100.0 \%)$ \\
\hline & \multicolumn{4}{|c|}{$\mathrm{p}$-value $=0.253$} & \multicolumn{5}{|c|}{$\mathrm{p}$-value $=0.068$} \\
\hline
\end{tabular}

Table 7. Distribution of Perspectives on Challenges of ID by Stakeholder Type

\begin{tabular}{|c|c|c|c|c|c|c|c|c|c|}
\hline \multirow[b]{2}{*}{ Challenges of ID } & \multicolumn{4}{|c|}{ Stakeholder type } & \multicolumn{5}{|c|}{ Stakeholder sector } \\
\hline & $\begin{array}{l}\text { Funder/D } \\
\text { onor }\end{array}$ & $\begin{array}{l}\text { Policy } \\
\text { Maker }\end{array}$ & $\begin{array}{l}\text { Programme } \\
\text { Manager }\end{array}$ & Total & $\begin{array}{l}\text { NGO or } \\
\text { Development } \\
\text { Sector }\end{array}$ & \begin{tabular}{|l|} 
Government \\
Ministry or \\
Parastatal \\
\end{tabular} & $\begin{array}{l}\text { Hospitals or } \\
\text { Other Health } \\
\text { Institutions }\end{array}$ & $\begin{array}{l}\text { Private } \\
\text { Sector }\end{array}$ & Total \\
\hline \multirow[t]{2}{*}{ Technical compromise } & 15 & 42 & 105 & 162 & 104 & 26 & 27 & 8 & 165 \\
\hline & $(55.6 \%)$ & $(55.3 \%)$ & $(57.1 \%)$ & $(56.4 \%$ & $(59.8 \%)$ & $(56.5 \%)$ & $(50.9 \%)$ & $(28.6 \%)$ & $(54.8 \%)$ \\
\hline \multirow[t]{2}{*}{ Complex processes } & 10 & 23 & 91 & 124 & 84 & 13 & 22 & 11 & 130 \\
\hline & $(37.0 \%)$ & $(30.3 \%)$ & $(49.5 \%)$ & $(43.2 \%$ & $(48.3 \%)$ & $(28.3 \%)$ & $(41.5 \%)$ & $(39.3 \%)$ & $(43.2 \%)$ \\
\hline \multirow[t]{2}{*}{ Capital intensive } & 16 & 32 & 72 & 120 & 72 & 15 & 27 & 10 & 124 \\
\hline & $(59.3 \%)$ & $(42.1 \%)$ & $(39.1 \%)$ & $(41.8 \%$ & $(41.4 \%)$ & $(32.6 \%)$ & $(50.9 \%)$ & $(35.7 \%)$ & $(41.2 \%)$ \\
\hline \multirow{2}{*}{$\begin{array}{l}\text { Difficult to coordinate and } \\
\text { manage }\end{array}$} & 13 & 37 & 85 & 135 & 87 & 21 & 22 & 7 & 137 \\
\hline & $(48.1 \%)$ & $(48.7 \%)$ & $(46.2 \%)$ & $(47.0 \%$ & $(50.0 \%)$ & $(45.7 \%)$ & $(41.5 \%)$ & $(25.0 \%)$ & $(45.5 \%)$ \\
\hline \multirow{2}{*}{$\begin{array}{l}\text { Requires longer project } \\
\text { duration }\end{array}$} & 9 & 25 & 67 & 101 & 63 & 15 & 17 & 11 & 106 \\
\hline & $(33.3 \%)$ & $(32.9 \%)$ & $(36.4 \%)$ & $(35.2 \%$ & $(36.2 \%)$ & $(32.6 \%)$ & $(32.1 \%)$ & $(39.3 \%)$ & $(35.2 \%)$ \\
\hline \multirow[t]{3}{*}{ Total } & 27 & 76 & 184 & 287 & 174 & 46 & 53 & 28 & 301 \\
\hline & $(100.0 \%)$ & $(100.0 \%)$ & $(100.0 \%)$ & $(100.0 \%)$ & $(100.0 \%)$ & $(100.0 \%)$ & $(100.0 \%)$ & $(100.0 \%)$ & $(100.0 \%)$ \\
\hline & \multicolumn{4}{|c|}{ p-value $=0.222$} & \multicolumn{5}{|c|}{$\mathrm{p}$-value $=0.028$} \\
\hline
\end{tabular}




\section{Influence of Stakeholder Characteristics on Perspectives of ID}

We examined gender, highest level of education attained, designation/job level, and number of years of experience in the sector.

Influence of gender on stakeholder perspective of ID

There were variations in the proportions of each gender reporting specific perspectives of the meaning of ID. The rank of the perspectives was however very similar for both sexes. What stood out the most for females $(73.3 \%)$ and for males $(67.6 \%)$ was that integrated development referred to multisectoral interventions. This was followed by the perspective that integrated development meant a pooling of resources (human, material and finance) by 46 females (39.7\%) and 77 males (41.6\%). There was no statistically significant difference in the pattern of perspectives for both sexes at the 5\% level. These results are presented in Table.

\section{Influence of Highest Level of Education on Stakeholder Perspective of ID}

The predominant response $(50.0 \%)$ from stakeholders with diploma as their highest level of education was that ID was joint implementation of two separate programs. For those with university education, ID was predominantly seen as a multi-sectoral intervention by those with Bachelor's degree (67.8\%) and Master's degree (72.5\%) alike. The perspective that ID is multisectoral intervention was the second most predominant perspective among those with a diploma (42.9\%). ID as integration of different methodologies or as holistic programming that connects various components were two perspectives that was not expressed by all stakeholders regardless of their highest level of education. The differences in proportions were statistically significant at the $5 \%$ level. See Table.

Table 8. Variations in Perspective of ID by Gender and Level of Education

\begin{tabular}{|c|c|c|c|c|c|c|c|}
\hline \multirow[b]{2}{*}{ Meaning of ID } & \multicolumn{3}{|l|}{ Gender } & \multicolumn{4}{|c|}{ Highest Level of Education Attained } \\
\hline & Female & Male & Total & Diploma & \begin{tabular}{|l|} 
Bachelor \\
Degree
\end{tabular} & $\begin{array}{l}\text { Master's Degree } \\
\text { and above }\end{array}$ & Total \\
\hline \multirow{2}{*}{ Multi-sectoral intervention } & 85 & 125 & 210 & 6 & 59 & 145 & 210 \\
\hline & $(73.3 \%)$ & $(67.6 \%)$ & $(69.8 \%)$ & $(42.9 \%)$ & $(67.8 \%)$ & $(72.5 \%)$ & $(69.8 \%)$ \\
\hline \multirow{2}{*}{$\begin{array}{l}\text { Pooling resources (human, } \\
\text { material and finance) }\end{array}$} & 46 & 77 & 123 & 0 & 18 & 73 & 91 \\
\hline & $(39.7 \%)$ & $(41.6 \%)$ & $(40.9 \%)$ & $(0.0 \%)$ & $(20.7 \%)$ & $(36.5 \%)$ & $(30.2 \%)$ \\
\hline \multirow{2}{*}{$\begin{array}{l}\text { Roundtable collaboration with } \\
\text { other stakeholders }\end{array}$} & 45 & 71 & 116 & 4 & 28 & 91 & 123 \\
\hline & $(38.8 \%)$ & $(38.4 \%)$ & $(38.5 \%)$ & $(28.6 \%)$ & $(32.2 \%)$ & $(45.5 \%)$ & $(40.9 \%)$ \\
\hline \multirow{2}{*}{ Central coordination mechanism } & 26 & 65 & 91 & 2 & 33 & 81 & 116 \\
\hline & $(22.4 \%)$ & $(35.1 \%)$ & $(30.2 \%)$ & $(14.3 \%)$ & $(37.9 \%)$ & $(40.5 \%)$ & $(38.5 \%)$ \\
\hline \multirow{2}{*}{$\begin{array}{l}\text { Joint implementation of two } \\
\text { separate programs }\end{array}$} & 32 & 56 & 88 & 0 & 15 & 40 & 55 \\
\hline & $(27.6 \%)$ & $(30.3 \%)$ & $(29.2 \%)$ & $(0.0 \%)$ & $(17.2 \%)$ & $(20.0 \%)$ & $(18.3 \%)$ \\
\hline \multirow{2}{*}{ Co-location of services } & 19 & 36 & 55 & 7 & 24 & 57 & 88 \\
\hline & $(16.4 \%)$ & $(19.5 \%)$ & $(18.3 \%)$ & $(50.0 \%)$ & $(27.6 \%)$ & $(28.5 \%)$ & $(29.2 \%)$ \\
\hline \multirow{2}{*}{$\begin{array}{l}\text { Integrating different } \\
\text { methodologies }\end{array}$} & 0 & 1 & 1 & 0 & 0 & 1 & 1 \\
\hline & $(0.0 \%)$ & $(0.5 \%)$ & $(0.3 \%)$ & $(0.0 \%)$ & $(0.0 \%)$ & $(0.5 \%)$ & $(0.3 \%)$ \\
\hline \multirow{2}{*}{$\begin{array}{l}\text { Holistic programming that } \\
\text { connects various components }\end{array}$} & 1 & 0 & 1 & 0 & 0 & 1 & 1 \\
\hline & $(0.9 \%)$ & $(0.0 \%)$ & $(0.3 \%)$ & $(0.0 \%)$ & $(0.0 \%)$ & $(0.5 \%)$ & $(0.3 \%)$ \\
\hline \multirow{3}{*}{ Total } & 116 & 185 & 301 & 14 & 87 & 200 & 301 \\
\hline & $(100.0 \%)$ & $(100.0 \%)$ & $(100.0 \%)$ & $(100.0 \%)$ & $(100.0 \%)$ & $(100.0 \%)$ & $(100.0 \%)$ \\
\hline & p-value $=$ & $=0.293$ & & $\mathrm{p}$-value $=$ & 0.003 & & \\
\hline
\end{tabular}




\section{Influence of Job Level on Stakeholder Perspective of ID}

For all job levels, ID was predominantly seen as multisectoral interventions. The highest proportion of junior $(65.9 \%)$, mid $(74.8 \%)$, and senior $(67.1 \%)$ level stakeholders shared the perspective of ID being multi-sectoral interventions. For all job levels, the perspectives that ID is integration of different methodologies or holistic programming that connects various components were not expressed. Other perspectives, as shown in Table, varied in predominance among different job levels. These variations were however not statistically significant at the $5 \%$ level.

\section{Influence of Years of Experience on Stakeholder Perspective of ID}

The perspective that ID is multi-sectoral intervention was the most expressed despite varying years of experience within different sectors. For those with less than 5 years of experience $(67.6 \%), 5$ to 10 years $(72.0 \%)$ and more than 10 years $(69.3 \%)$ of experience, multi-sectoral intervention was the perspective they held of ID. The proportion from those with 5 to 10 years' experience was the highest of the 3 groups. Those with 5 to 10 years' experience (46.2\%) were also the most likely to express that ID was a roundtable collaboration compared to those with less than 5 years $(36.8 \%)$ and those with more than 10 years' experience $(34.3 \%)$. Pooling resources as a perspective of ID was mostly expressed by stakeholders with more than 10 years of experience $(45.0 \%)$ compared to those with less than 5 years $(38.2 \%)$ or those with 5 to 10 years of experience $(36.6 \%)$. These patterns were statistically significant at the $5 \%$ level. The two perspectives - holistic programming and integrating different methodologies were not included in the test of significance calculations. These results are presented in Table.

Table 9. Variations in Perspectives of ID by Job Level and Years of Experience

\begin{tabular}{|c|c|c|c|c|c|c|c|c|}
\hline \multirow[b]{2}{*}{ Meaning of ID } & \multicolumn{4}{|c|}{ Designation/Job Level } & \multicolumn{4}{|c|}{ Number of Years Worked in the Sector } \\
\hline & $\begin{array}{l}\text { Junior } \\
\text { Level }\end{array}$ & $\begin{array}{l}\text { Mid- } \\
\text { Level }\end{array}$ & $\begin{array}{l}\text { Senior } \\
\text { Level }\end{array}$ & Total & $\begin{array}{l}\text { Less than } \\
5 \text { Years }\end{array}$ & $\begin{array}{l}\text { 5-10 } \\
\text { Years }\end{array}$ & $\begin{array}{l}\text { More than } \\
10 \text { Years }\end{array}$ & Total \\
\hline \multirow{2}{*}{$\begin{array}{l}\text { Multi-sectoral } \\
\text { intervention }\end{array}$} & 27 & 83 & 100 & 210 & 46 & 67 & 97 & 210 \\
\hline & $(65.9 \%)$ & $(74.8 \%)$ & $(67.1 \%)$ & $(69.8 \%)$ & $(67.6 \%)$ & $(72.0 \%)$ & $(69.3 \%)$ & $(69.8 \%)$ \\
\hline \multirow{2}{*}{$\begin{array}{l}\text { Pooling resources } \\
\text { (human, material } \\
\text { and finance) }\end{array}$} & 16 & 44 & 63 & 123 & 26 & 34 & 63 & 123 \\
\hline & $(39.0 \%)$ & $(39.6 \%)$ & $(42.3 \%)$ & $(40.9 \%)$ & $(38.2 \%)$ & $(36.6 \%)$ & $(45.0 \%)$ & $(40.9 \%)$ \\
\hline \multirow{2}{*}{$\begin{array}{l}\text { Roundtable } \\
\text { collaboration } \\
\text { with other } \\
\text { stakeholders }\end{array}$} & 12 & 47 & 57 & 116 & 25 & 43 & 48 & 116 \\
\hline & $(29.3 \%)$ & $(42.3 \%)$ & $(38.3 \%)$ & $(38.5 \%)$ & $(36.8 \%)$ & $(46.2 \%)$ & $(34.3 \%)$ & $(38.5 \%)$ \\
\hline \multirow{2}{*}{$\begin{array}{l}\text { Central } \\
\text { coordination } \\
\text { mechanism }\end{array}$} & 9 & 31 & 51 & 91 & 9 & 38 & 44 & 91 \\
\hline & $(22.0 \%)$ & $(27.9 \%)$ & $(34.2 \%)$ & $(30.2 \%)$ & $(13.2 \%)$ & $(40.9 \%)$ & $(31.4 \%)$ & $(30.2 \%)$ \\
\hline \multirow{2}{*}{$\begin{array}{l}\text { Joint } \\
\text { implementation } \\
\text { of two separate } \\
\text { programs }\end{array}$} & 13 & 31 & 44 & 88 & 21 & 30 & 37 & 88 \\
\hline & $(31.7 \%)$ & $(27.9 \%)$ & $(29.5 \%)$ & $(29.2 \%)$ & $(30.9 \%)$ & $(32.3 \%)$ & $(26.4 \%)$ & $(29.2 \%)$ \\
\hline \multirow{2}{*}{$\begin{array}{l}\text { Co-location of } \\
\text { services }\end{array}$} & 3 & 18 & 34 & 55 & 5 & 23 & 27 & 55 \\
\hline & $(7.3 \%)$ & $(16.2 \%)$ & $(22.8 \%)$ & $(18.3 \%)$ & $(7.4 \%)$ & $(24.7 \%)$ & $(19.3 \%)$ & $(18.3 \%)$ \\
\hline
\end{tabular}




\begin{tabular}{|c|c|c|c|c|c|c|c|c|}
\hline \multirow{2}{*}{$\begin{array}{l}\text { Holistic } \\
\text { programming } \\
\text { that connects } \\
\text { various } \\
\text { components }\end{array}$} & 0 & 0 & 1 & 1 & 0 & 0 & 1 & 1 \\
\hline & $(0.0 \%)$ & $(0.0 \%)$ & $(0.7 \%)$ & $(0.3 \%)$ & $(0.0 \%)$ & $(0.0 \%)$ & $(0.7 \%)$ & $(0.3 \%)$ \\
\hline \multirow{2}{*}{$\begin{array}{l}\text { Integrating } \\
\text { different } \\
\text { methodologies }\end{array}$} & 0 & 0 & 1 & 1 & 0 & 0 & 1 & 1 \\
\hline & $(0.0 \%)$ & $(0.0 \%)$ & $(0.7 \%)$ & $(0.3 \%)$ & $(0.0 \%)$ & $(0.0 \%)$ & $(0.7 \%)$ & $(0.3 \%)$ \\
\hline \multirow[t]{3}{*}{ Total } & 41 & 111 & 149 & 301 & 68 & 93 & 140 & 301 \\
\hline & $(100.0 \%)$ & $(100.0 \%)$ & $(100.0 \%)$ & $(100.0 \%)$ & $(100.0 \%)$ & $(100.0 \%)$ & $(100.0 \%)$ & $\begin{array}{l}(100.0 \% \\
)\end{array}$ \\
\hline & \multicolumn{4}{|c|}{$\mathrm{p}$-value $=0.509$} & \multicolumn{4}{|c|}{$\mathrm{p}$-value $=0.011$} \\
\hline
\end{tabular}

\section{Discussion}

This study surveyed stakeholders' perspectives of integrated development, determined the influence of stakeholder characteristics on these perspectives in Nigeria and here discusses these findings. Overall, stakeholders in Nigeria largely agreed that ID was beneficial, yielding more impactful and sustainable development outcomes. There was convergence in the perspectives of stakeholders on the perspective that ID could mean multisectoral interventions, a central coordination mechanism and pooling of resources (human, material and finance). Areas of convergence also included perspectives that ID involved effective collaboration, communication, consensus, and cost-effectiveness. There was concomitant divergence in the perspectives of stakeholders on what constituted benefits of ID with less than $30 \%$ of private sector stakeholders considering cost-effectiveness as a benefit - the lowest of any stakeholder sector. Additionally, stakeholder perspectives were divergent on what constituted challenges of ID especially with longer project duration not considered a factor by development sector stakeholders. These variations in perspectives might reflect the interest of different stakeholders and were distilled into the measurement framework which had at the core, an acceptance of the fact that there will always be convergence and divergence of stakeholder perspectives but that these were not necessarily a hindrance neither to ID nor to the measurement of its impact.

Most stakeholders generally viewed ID positively with an expectation that it delivers benefits to both funders and beneficiaries. This aligns with submissions from authors who expressed that despite the diverse definitions and forms, or lack of robust evaluations of ID, the general expectation is for ID to enhance service efficiency, quality, and maximize the use of resources and opportunities [19, 20]. Indeed, Shigayeva and colleagues who reviewed the ID literature in 2010, found that, broadly, integrated development is viewed positively in relation to health systems including benefits such as reducing fragmentation or duplication of services, improving patient care outcomes and resulting in greater satisfaction from services, benefits to overall population health, and improved performance of health systems, their programmes, and services [33]. The findings of this study highlighted a predominant perspective of integrated development as a collaborative approach to implementing interventions across and within sectors to achieve higher impact and cost efficiencies. This perspective cuts across all stakeholders.

The notion that ID could mean various things to various stakeholders also came to the fore in this research. Indeed, in exploring perspectives, it was evident that different stakeholders held different perspectives on many elements of ID. 
At the same time, there were also many occasions when the perspectives were totally aligned. These points of divergence and convergence are important in framing ID for multiple stakeholders. To be acceptable, ID must be presented in a way that the stakeholder can identify with. For instance, a higher proportion of funders/donors (55.6\%) expected ID to always be intersectoral when compared to policy makers $(30.3 \%)$ and program managers $(37.7 \%)$. This understanding of the variations in stakeholder perspectives can be important in ID engagements. This point also takes further strength from the fact that multiple authors have described multiplicity of meanings and lack of clarity where ID is used [7, 34]. It adds impetus to the fact that during integrated development discussions, the application should be clearly specified - within or across sectors and which specific sector(s).

Stakeholders from different sectors might be exposed to different influences, expectations and outlook to development which reflects in their perspectives of integrated development. In my research, stakeholders from the development sector and government ministry had similar patterns in the way they expressed what they perceived as the meaning of ID, the patterns were different among hospital-based and private sector stakeholders. Overall, though, regardless of stakeholder sector, the majority of stakeholders perceived ID to mean multisectoral interventions. This might signify an acceptance of the need to work across sectors which is essential for success. It has been posited, that the term integrated development evokes an image which may be sufficient for the intended aim to stimulate thinking about cross-sectoral action for development.

All groups of stakeholders shared the perspective that integrated development is associated with increased coverage of services with multiplied benefits to served communities and individuals. This is one of the generally held perspectives of integrated development [19, 35]. Authors have however also argued that this perspective is mostly intuitive without rigorous evidence to substantiate such expectations [3638]. Nonetheless, this generally held perspective is one that portends a good future for integrated development. It is striking that most funders/donors (70.4\%) expressed enhancing collaborations and strengthening human capacity as the main benefit over other benefits. Most policy makers (78.9\%) and program managers $(78.3 \%)$ expressed that ID yields more impactful and sustainable interventions as their predominant benefit. This is likely tied directly to the fact that the funder/donor may be interested in strengthening systems as a means to delivering what is the desire of the policy maker - sustainable impact. It was unexpected to see that cost effectiveness was the least mentioned benefit by funders/donors (51.9\%) and programme managers (59.2\%). Cost effectiveness would have been thought to be a keen item on the agenda of funders/donors in particular. In this wise, my findings deviate from those of were least likely to consider as a benefit. More insights on cost are further discussed below.

As regards perspectives on the benefits of ID, enhancing collaborations and strengthening human capacity was the predominant benefit among funders/donors (70.4\%), and the second most expressed benefit among policy makers (71.1\%) and programme managers (78.3\%). Funders/donors might be keen on expanding collaborations and strengthening human resource capacity as a means of entrenching sustainability of interventions. While this may rank high on the agenda of policy makers, the most predominantly expressed benefit among the policy makers $(78.9 \%)$ and programme managers $(78.3 \%)$ was that ID yields more impactful and sustainable interventions. It would seem therefore that policy makers opted to express benefits in terms of the desired outcome - sustainable interventions, ranking this ahead of the process - enhancing collaborations and strengthening human resource capacity. While one might be tempted to see this as a minor 
difference, it is one of immense importance. The funder/donor may be more interested in ensuring the processes are sound and well-structured in order to achieve desired outcomes while policy makers may be more focused on the outcome, leaving the details of processes to program managers or others within the chain. Of all the benefits listed, the least likely benefit expressed by policy makers was that ID enhances communication.

To funders, integrated development may contribute to cost efficiencies or enhanced sustainability. Suther, et. al mentioned that integrated health systems would contribute to economic benefits because of savings from implementation scale and cost reductions in administrative and case management [35]. However, in a technical paper by WHO [39], integration does not automatically generate savings, but integrating new activities into the existing system may need additional resources.

It is striking to note that all stakeholders expressed cost efficiencies as a benefit of integrated development. While Suther, et. al [35] had reported that funders were more likely to emphasize cost efficiency and sustainability, my research had a slightly different finding. Indeed, only program managers shared a perspective of cost related to sustainability. That all three groups of stakeholders would express cost efficiencies as a perspective can be viewed against the findings of Ringheim and colleagues [40]. They had noted that an ID approach can help the health system save costs by 'using common space, reducing staff costs, and lowering overhead' [40]. Another scholar had mentioned that integrated health systems would contribute to economic benefits because of savings from implementation scale and cost reductions in administrative and case management [35]. These are elements that would be of importance to all groups of stakeholders. Although cost efficiencies were universally expressed, stakeholders also expressed concerns that integrated development may be initially costly. This view was similar to those expressed in a 2008 technical paper by WHO. Integrated development is said to not automatically generate savings, as additional resources may be needed to implement an integrated approach [39]. This initial investment in integration processes may result in increased costs before they can provide savings [35] particularly when integrating new processes into existing processes [39].

One perspective that was uniquely expressed by policymakers was that of trade-offs being necessary to achieve integrated development. This perspective was expected for this group of stakeholders who have to contend with merging budgets, monitoring systems and policy evaluations from different components of an integrated development effort [21]. Interviewed policymakers expected to not be able to measure constituent parts of an integrated development effort as robustly as they would measure the individual components. Richey [41] had also written that policy makers could also express apprehensions about the compatibility of systems, particularly on the information management systems. What was not mentioned at all by our stakeholders was the area of legislation in policy making. It has been suggested that integrated development can be applied right from legislation enactment in support of policies [42].

There was general agreement by all stakeholders that there were challenges with ID. Where variations ensued was in the specific items that constituted the challenges. The variations somewhat reflected the interests of each stakeholder type. For instance, a challenge that was elicited during the qualitative enquiry was that ID projects may lead to technical compromise as each constituent technical area would have to forgo certain elements for an integrated approach. This line of thought was also expressed and discussed above as trade-offs being necessary for ID. When quantitatively assessed, most stakeholders from the development sector (59.8\%), government ministries $(56.5 \%)$ and health institutions 
(50.9\%) listed technical compromise as a challenge with ID. This can be both worrisome and encouraging. Worrisome if this predominating perspective pushes stakeholders away from considering integrated approach as desirable. It can be encouraging if this perspective pushes stakeholders to seek ways to address technical quality on integrated development projects. Majority of respondents from the private sector $(39.3 \%)$ however considered complex processes and requiring longer project durations as their major challenges. This is to be expected as the private sector, often focused on efficient processes and quick outcomes may lack the patience to wait on long processes before demonstrating outcomes. The development sector (36.3\%) and health institution based (32.1\%) stakeholders were least likely to report requiring longer project duration as a challenge with ID. For the development sector, especially those who work on projects, a long duration may be seen as a stable job and therefore, long durations would not be expected to be a challenge. For hospital-based stakeholders usually with long term, employments, there is no hurry to see outcomes and therefore, long project durations are expectedly not to be considered problematic. Government ministry stakeholders were on the other hand least likely to report complex processes as their challenge with ID. This may be due to familiarity with long bureaucratic processes that often characterize ministry procedures.

In further considerations of challenges with integrated development, funders/donors expressed that differing views from stakeholders in integrated development may make the process challenging. Harmonizing the different expectations and fitting them within a common agenda was seen as a difficult task. The importance of this harmonization of views to integrated development has however been emphasized by authors [24, 43]. Establishing a system requires cooperation and collaboration among the several players to work together in achieving common goals and results [44]. Without getting to a shared agenda, there can be no integrated development [24]. Program managers shared this perspective of ensuring a shared agenda even though their focus was more on the cost needed at the early stages to be spent on human resources. Policy makers considered the cost of coordination platforms, meetings and materials. It becomes obvious then that while different stakeholder groups may refer to the same elements in describing their perspectives, in this instance cost, those elements may not necessarily refer to the same components. For instance, while cost was being referred to, program managers talked about this in respect of building human resource capacity, policymakers discussed collaboration costs and funders considered costs of program inputs. In practice therefore, there must be sufficient clarity about the components of integrated development being discussed [39, 44, 45].

The necessity of integrated development to tackle the challenges that individuals and their families face which tend to perpetuate the cycle of ignorance, poverty and disease has been argued for by many authors [2-12]. The argument for integrated development often stems from the recognition that poor development is rooted in multiple interplaying factors from different sectors. Irrespective of the development school of thought to which authors belong, there is a general agreement that development is about improvement in standards of living and these improvements are usually not from a single sector $[13,14]$.

A glaring output from the foregoing is that since stakeholders come from different backgrounds, work in different settings, are exposed to different influences and pursue different interests within the development space, it is plausible to expect that their perspectives will be different as found in this study. Again, while they may hold different perspectives, there are areas of convergence in perspectives where perspectives are aligned. These points of divergence and convergence are important in 
framing ID for multiple stakeholders. Indeed, each stakeholder may hold on strongly to their perspectives and these different stakeholder views often determine what is considered success or failure [21]. This drives to the heart of the measurement of impact of integrated development. Stakeholder expectations must be understood and then used to frame the integrated development discourse, and subsequent design of interventions including measurement of impact. It is also important to understand that there may be apprehensions by different stakeholder groups that may impact practice [41].

\section{Conclusion}

Stakeholder perspectives of integrated development in Nigeria included those of perceived benefits and concerns. There is an alignment of perspectives among key

\section{References}

[1] FHI 360, Defining Integrated Development at FHI 360. 2016, FHI 360: Washington DC.

[2] Holveck, J.C., et al., Prevention, control, and elimination of neglected diseases in the Americas: pathways to integrated, inter-programmatic, intersectoral action for health and development. BMC Public Health, 2007. 7: p. 6.

[3] WHO, Rio Political Declaration on Social Determinants of Health, in World Conference on Social Determinants of Health. 2011, World Health Organization: Rio de Janeiro, Brazil.

[4] Van Minh, H., et al., Millennium Development Goals in Vietnam: Taking Multi-sectoral Action to Improve Health and Address the Social Determinants. Glob Health Action, 2016. 9: p. 31271.

[5] UNDP, Human Development Report 2016. 2016, United Nations Development Programme: New York.

[6] Sheikh, M.R., et al., Multisectoral development for improved health outcomes: evaluation of community-based initiatives in the Islamic Republic of Iran. East Mediterr Health J, 2010. 16(12): p. 12316. stakeholder groups especially with regards to potential benefits of integrated development. While stakeholders may agree that cost could be a challenge, the cost elements of focus are unique to each stakeholder group. This and other uniquely held perspectives create implications for the way integrated development as an approach should be addressed when communicating with each stakeholder and when trying to achieve consensus for program development and monitoring.

\section{Conflict of Interest}

The authors declare no conflict of interest.

\section{Acknowledgments}

The authors would like to acknowledge the contributions of Omosalewa Oyelaran, Auwalu Kawu, Mariya Saleh and Hadiza Khamofu.

[7] Harris, J. and A. Buchsbaum, Growing Together? Experiences of Intersectoral Integration in an NGO Nutrition Program: A Study of HKI's Enhanced Homestead Food Production Model in Burkina Faso. 2014, USAID/Strengthening Partnerships, Results, and Innovations in Nutrition Globally (SPRING) Project: Arlington, VA.

[8] Green, G., Intersectoral planning for city health development. J Urban Health, 2012. 89(2): p. 247-57. [9] Gonzales, F., K. Dearden, and W. Jimenez, do multi-sectoral development programmes affect health? A Bolivian case studies. Health Policy Plan, 1999. 14(4): p. 400-8.

[10] Glouberman, S., et al., A toolbox for improving health in cities: a discussion paper. 2003, Caledon Institute of Social Policy: Ottawa.

[11]Gakh, M., Law, the health in all policies approach, and cross-sector collaboration. Public Health Rep, 2015. 130(1): p. 96-100.

[12]Fulop, T., New approaches to a permanent problem. The integrated development of health services and health manpower. WHO Chron, 1976. 30(11): p. 433-41. 
[13] Ulfelder, J., Development as Ideology, in Dartthrowing chimp - thoughtful analysis or bloviation? your call. 2013.

[14] Odey, M.O., A Critique of the Notion of Africa as the "Third World": Towards a New Perspective, in The Political Economy of Development and Underdevelopment in Africa, T. Falola and J. Achberger, Editors. 2013, Routledge: New York.

[15]UNDP, Human Development Report 1992. 1992, United Nations Development Programme: Oxford.

[16]UNDP, Human Development Report 1990. 1990, United Nations Development Programme: Oxford.

[17] Haq, M.u., Reflections on human development: how the focus of development economics shifted from national income accounting to people-centred policies, told by one of the chief architects of the new paradigm. 1995, New York: Oxford University Press. [18]Easterly, W. The Ideology of Development. Foreign Policy, 2009.

[19] Paulus, A., et al., Integrated health care from an economic point of view. Journal of Economic Studies, 2000. 27(3): p. 200-210.

[20]Briggs, C.J. and P. Garner, Strategies for integrating primary health services in middle- and low-income countries at the point of delivery. Cochrane Database of Systematic Reviews, 2006(2).

[21]FHI 360, Guidance for Evaluating Integrated Global Development Programs. 2016, FHI 360: Washington DC.

[22]Lloyd, J. and S. Wait, Integrated Care: a Guide for Policymakers. 2006, London: Alliance for Health and the Future.

[23] Bautista, M.A.C., et al., Instruments Measuring Integrated Care: A Systematic Review of Measurement Properties. The Milbank Quarterly, 2016. 94(4): p. 862-917.

[24] Kania, J. and M. Kramer, Nonprofit Management: Collective impact, in Stanford Social Innovation Review. 2011, Leland Stanford Jr University: Stanford, CA.

[25] SEED Foundation. Government parastatals and agencies in Abuja. 2019 [cited 2019 22nd April]; Available from: https://www.abujang.com/parastatals-agencies-in-abuja.html
[26] SEED Foundation. NGOs in Abuja Nigeria. 2019 [cited 2019 22nd April]; Available from: https://www.abuja-ng.com/ngos-in-abuja.html.

[27] SEED Foundation. International Organizations and their Offices in Abuja. 2019 [cited 2019 22nd April]; Available from: https://www.abujang.com/international-organizations.html.

[28] SEED Foundation. Federal Ministries in Abuja. 2019 [cited 2019 22nd April]; Available from: https://www.abuja-ng.com/federal-ministries-inabuja.html.

[29] Gill, J. and P. Johnson, Research methods for managers. 4th ed. 2010, London: SAGE.

[30] Price, P.C., R.S. Jhangiani, and I. Chiang, Research methods in psychology - 2nd Canadian Edition. 2015, Victoria, B.C.: BC Campus.

[31]IBM Corp., IBM SPSS Statistics for Windows, Version 25.0. 2017, IBM Corp.: Armonk, NY.

[32] George, D. and P. Mallery, SPSS for Windows Step by Step: A Simple Guide and Reference. 11.0 update. 4th ed. 2003, Boston: Allyn \& Bacon.

[33] Shigayeva, A., et al., Health systems, ommunicable diseases and integration. Health Policy and Planning, 2010. 25(suppl_1): p. i4-i20.

[34] Contandriopoulos, A.-P., et al., The integration of health care: Dimensions and implementation. 2003.

[35] Suther, E., et al., Ten Key Principles for Successful Health Systems Integration. Healthc Q, 2009: p. 13 (Spec No.): 16-23.

[36] Teague, J., E. Johnston, and J. Graham, Water, sanitation, hygiene, and nutrition: successes, challenges, and implications for integration. International Journal of Public Health, 2014: p. DOI: 10.1007/s00038-014-0580-8.

[37] Sachs, J.D., Lessons from the Millennium Villages Project: a personal perspective. The Lancet Global Health, 2018. 6(5): p. e472-e474.

[38]FHI 360, Integration of global health and other development sectors: A review of the evidence. 2016, FHI 360: Washington DC.

[39] WHO, Integrated Health Services-What and Why, in Technical Brief No. 1. 2008, World Health Organization: Geneva.

[40]Ringheim, K., J. Gribble, and M. Foreman, Policy Brief: Integrating Family Planning and 
Maternal and Child Health Care: Saving Lives, Money, and Time. 2011, Population Reference Bureau Washington.

[41]Richey, L.A., HIV/AIDS in the Shadows of Reproductive Health Interventions. Reproductive Health Matters, 2003. 11(22): p. 30-35.

[42] WHO, WHO: Advancing the right to health: the vital role of law. Geneva: World Health Organization., 2017.

[43] Swanson, R., et al., Rethinking health systems strengthening: key systems thinking tools and strategies for transformational change. Health Policy Plan, 2012: p. 27(Suppl 4):54-61.

[44] Kodner, D.L. and C. Spreeuwenberg, Integrated care: meaning, logic, applications, and implications-a discussion paper. Int J Integr Care, 2002. 2: p. e12. [45] Mooss, A., M. Hartman, and G. Ibanez, Manual development: A strategy for identifying core components of integrated health programs. Eval Program Plann, 2015. 53: p. 57-64. 